\title{
The use of probiotics and safety concerns: A review
}

\author{
K Suresh Babu Naidu ${ }^{1 *}$, Jamila K Adam ${ }^{1}$ and Patrick Govender ${ }^{2}$ \\ ${ }^{1}$ Department of Biomedical and Clinical Technology, Durban University of Technology, Durban-4000, South Africa. \\ ${ }^{2}$ Department of Biochemistry, University of KwaZulu-Natal, Private Bag X54001, Durban 4000, South Africa.
}

Accepted 22 August, 2012

\begin{abstract}
Probiotics are defined as "live microorganisms which when administered in adequate amounts confer a health benefit on the host". Most probiotics fall into the group of organisms' known as lactic acidproducing bacteria and are normally consumed in the form of yogurt, fermented milks, cereal or other fermented foods. Many of the products currently available in the market are not clearly tied to research documenting beneficial effects. Probiotics are regulated by FDA and several reports are available now for mislabeling the product claiming health benefits. As live microbial products, probiotics are potential sources of risk and there exists skeptical attitude among medical professionals and consumers who have less than optimal experiences with probiotics. This review outlines information regarding probiotics, overview of proposed regulatory guidelines and commercial probiotic products available in the market considered as safe for humans.
\end{abstract}

Key words: Probiotics, health benefits, safety, dosage, applications.

\section{INTRODUCTION}

The term 'probiotics' was derived from the Greek word, meaning "for life" (Reid et al., 2003). An expert panel commissioned by Food and Agriculture Organization (FAO) and World Health Organization (WHO) defined probiotic as "live micro-organisms," which, when administered in adequate amounts confers a health benefits on the host (FAO/WHO, 2006). Recently, there is an increasing scientific and commercial interest in the use of beneficial microorganisms for the prevention and treatment of diseases (Figure 1). The use of microorganisms to restore or maintain health is the basis of probiotics which is one of the largest segments of the functional foods (FF) market. The global sales of probiotic supplements were predicted to rise $48 \%$ from $\$ 2.7 \mathrm{bn}$ in 2011 to \$4bn in 2016 (www.nutraingredients.com/ Consumer-Trends). In US, per capita spending on probiotic supplements is expected to nearly double by 2016 and overtake Japan. Indeed, the market of probiotics and healthy food has great potential to grow, especially in Asia. However, the European market is now saturated, and growth of probiotic market is likely to occur mainly in non-dairy food areas and novel applications

*Corresponding author. E-mail: dr.naidu@hotmail.com. Tel: +27-31-3735291. Fax: +27-31-3735255.
(Rivera-Espinoza and Gallardo-Navarro, 2010). The different bacterial genera most commonly used in probiotic preparations are Lactobacillus, Bifidobacterium, Escherichia, Enterococcus, Bacillus, Streptococcus and Pediococcus (Adam et al., 2012). Some fungal strains belonging to Saccharomyces (Saccharomyces boulardii) are now used as a "drug" to prevent or treat recurrent Clostridium difficile infection (CDI), particularly in critically ill patients (Gupta and Garg, 2009; Mc Farland, 2009). This review focuses on highlighting the current regulatory framework, risks associated, dosage and probiotic products currently available in the market for human consumption for various treatments.

\section{Occurrence and action of probiotics}

Most existing probiotics have been isolated from the human gut microbiota. This microbiota plays an important role in human health, not only due to its participation in the digestion process, but also for the function it plays in the development of the gut and the immune system (Sanchez et al., 2012). The human gastrointestinal (Gl) tract is "home" to a complex consortia of trillions (approximately $1 \times 10^{13}$ to $1 \times 10^{14}$ ) of microbes, thousands of bacterial phylotypes, as well as hydrogenconsuming methanogenic archaea, colonizing the entire 


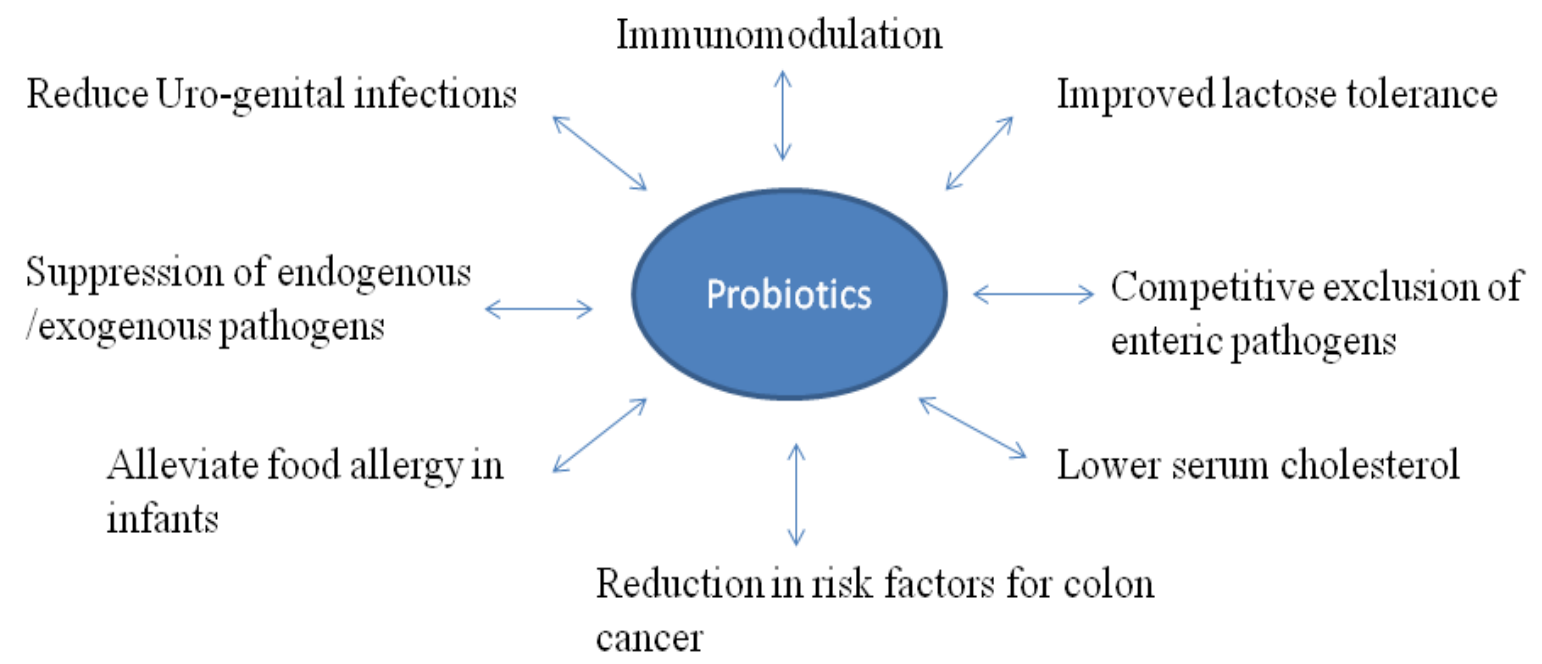

Figure 1. Health benefits of probiotics.

length of the gut with a collective genome (also termed as microbiome) that contains at least 100-times as many genes as our own genome (Cho and Blaser, 2012; Wei et al., 2008). Cutting edge research and vast accumulating data indicates that the gut microbiota is instrumental in energy metabolism and immune function of the host, and has a crucial role in the development of numerous conditions including obesity (Clarke et al., 2012; Ley et al., 2006) diabetes (Bergman et al., 2006), non-alcoholic fatty liver disease (Dumas et al., 2006), inflammatory bowel diseases (Quigley, 2012; Strober et al., 2008), and cancer (Parvez et al., 2006). Mechanism of action of probiotics is not completely understood, however as general include 1) Adherence and colonization of gut, 2) Suppression of growth of pathogenic bacteria, 3) Production of antimicrobial compounds, 4) Improved intestinal barrier function, 5) Stimulation of mucosal and systemic host immunity, 6) Controlled transfer of dietary antigens (Sharma et al., 2012).

\section{Registering probiotic product}

Regulatory issues are of prime focus for those involved in the development and marketing of probiotic products. The European Food Safety Authority (EFSA) recently determined that none of the claims for specific probiotic strains submitted to date were adequately substantiated by the scientific data that were provided as evidence of support (EFSA, 2009). Health Canada recently provided industry guidance on probiotic-containing foods (http: //www.hc-sc. gc.ca) and is developing guidance for probiotic natural health products. The Indian Council of Medical Research (ICMR) is developing guidelines for India that would require probiotic strains to be backed by clinical trials preferably conducted in local population, if they are to be marketed (Gokhale and Nadkarni, 2007). Recently, Shane et al. (2010) developed a guide for the design of well performed, randomized, controlled clinical studies in human participants in order to provide acceptable evidence to support a probiotic claim.

Although the concept of probiotics is not new, the advent of commercial products has refocused attention on their potential uses and applications. However, in the last few years new probiotic products have been introduced onto the market, with the inevitable competition for the consumers' disposable income. Additionally, the products have been introduced to health care professionals with a variety of therapeutic claims for health and benefit, often with extrapolated clinical evidence of efficacy (Elliott and Teversham, 2004).

Probiotics in the United States could potentially be regulated in a variety of different product range depending on the intended use either as Conventional foods (For consumption by general population), Dietary supplements (A subcategory of foods, the dietary supplement category was created in 1994 by the Dietary Supplement Health and Education Act- the products are meant to be used as oral supplements to the diet, and are not to be represented as meals), Medical foods (Foods used under medical supervision for patients needing special dietary support for medical condition), Feed additives (Termed "Direct fed microbials" by the USDA) or as Drugs (www.usprobiotics.org). According to the Food and Drug Administration (FDA) definition, a drug is an article intended for use in the diagnosis, cure, mitigation, treatment, or prevention of disease (FDA, 2009). If a probiotic is intended for use as a drug, then it must undergo the regulatory process as a drug, which is similar to that of any new therapeutic agent. Sanders (2009), in effectively choosing a product by both health care providers and consumers recommends that any new 


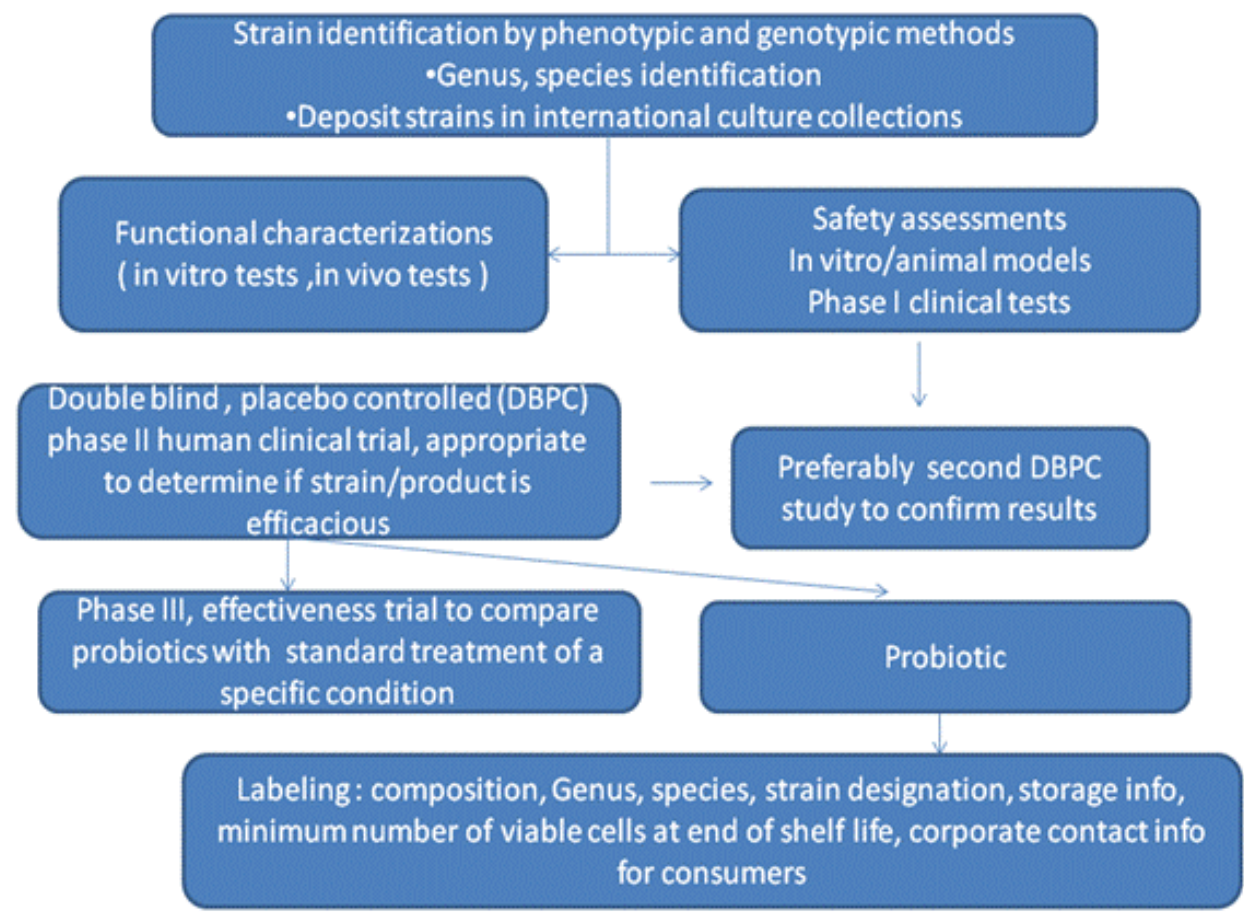

Figure 2. FAO/WHO Guidelines for the evaluation of probiotics for food use.

drug under investigation must be submitted and approved by FDA as safe and effective before an investigational or biological product can be administered to humans.

In an attempt to standardize the global requirements needed to make health claims regarding probiotic agents, the Joint Food and Agriculture Organization of the United Nations/World Health Organization Expert Consultation on Evaluation of Health and Nutritional Properties of Probiotics developed guidelines for evaluating probiotics in food that could lead to the substantiation of health claims. The recommended evaluation of probiotics for food use is shown in Figure 2. Consensus on uniform regulations is desirable to ensure identity, quality manufacturing processes, accurate labeling, proven safety and efficacy for a product that will carry the label "probiotic".

\section{Safety of probiotics}

The absolute essence of Probiotics to be considered as safe is the absence of pathogenicity and infectivity. Safety criteria for successful probiotics have been well defined in several studies (Forssten et al., 2011; Pineiro and Stanton, 2007; Mattila and Saarela, 2000; Saarela et al., 2000).

The fact to prove that the probiotic bacteria are infective is difficult, especially in anaerobes, which are generally considered to have no infectivity. Even if the bacteria are administered orally, infection does not normally occur in healthy animals; this is particularly so for bacteria with weak infectivity. Even with strongly infective bacteria, it is not easy to establish infection by using a single species, and various techniques are necessary to establish infection, such as the use of various pre-treatments in the experimental system or the use of mixed infection. Adverse effects of probiotics, if they occur, are usually mild and affect the digestive system in children (e.g., abdominal discomfort or flatulence) with short gut syndrome (Oliver and Reid, 2009; Kligler et al., 2007). However, as viable and potent microorganisms, probiotics have the potential to cause invasive infections in hosts who may have compromised mucosal epithelia. Invasive infections have primarily been noted to occur in immunocompromised adults. It is advisable to avoid probiotics in these patients or to be aware of risk of sepsis.

Lactobacillus species are a rare but well-recognized cause of endocarditis in adults (and other forms of sepsis in children) in the absence of probiotic supplementation. Several reports have directly linked cases of Lactobacillus and other bacterial sepsis to the ingestion of probiotic supplements. The reader is suggested to consult Boyle et al. (2006) for in-depth review of this subject. A proposed scheme for safety assessment of probiotics is presented in Table 1. Most stringent studies have to be completed for genetically modified strains intended for human consumption before commercialization (Choi et al., 2012; Sorokulova, 2008; Salminen et al., 1996). 
Table 1. Important studies for safety assessment of probiotic lactic acid bacteria (LAB) and other bacteria (Donohue and Salminen, 1996).

\begin{tabular}{|c|c|}
\hline Type of property studied & Safety factor to be assessed \\
\hline $\begin{array}{l}\text { Intrinsic properties of lactic acid } \\
\text { bacteria }\end{array}$ & $\begin{array}{l}\text { Adhesion factors, antibiotics resistance, existence of plasmids and Tra genes, harmful enzyme } \\
\text { profiles }\end{array}$ \\
\hline Metabolic products & Concentrations, safety and other effects \\
\hline Toxicity studies & Acute and subacute effects of ingestion of large amounts of tested bacteria \\
\hline Mucosal effects & $\begin{array}{l}\text { Adhesion, invasion potential, intestinal mucus degradation, infectivity in immunocompromised } \\
\text { animals }\end{array}$ \\
\hline Dose response effects & Dose response studies by oral administration in volunteers \\
\hline Clinical assessment & Potential for side effects, careful evaluation in healthy volunteers and disease specific studies \\
\hline Epidemiological studies & Surveillance of large populations following introduction of new strains and products \\
\hline
\end{tabular}

Table 2. Probiotic preparations.

\begin{tabular}{|c|c|c|}
\hline Probiotic strain & Recommended daily dosage & Preparations \\
\hline $\begin{array}{l}\text { Lactobacillus } \\
\text { rhamnosus GG }\end{array}$ & 10 billion CFUs & Capsules (Culturelle) Therapeutic yogurts and fermented milks \\
\hline $\begin{array}{l}\text { Lactobacillus sp./ } \\
\text { Bifidobacterium sp }\end{array}$ & $\begin{array}{l}100 \text { million to } 35 \text { billion CFUs, } \\
\text { depending on preparation }\end{array}$ & $\begin{array}{l}\text { Capsules (Align, Primadophilus) Powder (Primal Defense) Capsules or powder (Fem-Dophilus, } \\
\text { Jarro-Dophilus) Therapeutic yogurts and fermented milks (Activia, Danactive, Yo-Plus) }\end{array}$ \\
\hline Saccharomyces Boulardii & $250 \mathrm{mg}$ to $500 \mathrm{mg}$ & Capsules (Florastor) \\
\hline Bacillus sp & $10^{7}-10^{8}$ spores $g^{-1}$ & Powder (Bibactyl) \\
\hline
\end{tabular}

${ }^{a} \mathrm{CFU}=$ colony-forming unit, ${ }^{b}$ Most commercial brands contain a mixture of strains that may include Lactobacillus acidophilus, L. rhamnosus, Lactobacillus bulgaricus, Bifidobacterium bifidum, Bifidobacterium longum, and others. Exact combinations of strains vary among brands (www.usprobiotics.org).

\section{The right dosage}

Probiotics are generally sold as capsules, powder, tablets, liquid, or are incorporated into food. The specific number of colony forming unit (CFUs) contained in a given dose or serving of food can vary between brands (Kligler and Cohrssen, 2008). Patients should be advised to read products label carefully to make sure that they are getting the right dose. Interestingly, probiotics are available over the counter and are not regulated by FDA but generally regarded as safe. Because probiotics are not regulated by the FDA, there are no standard dosage recommendations for probiotics. Providers typically use half the adult dose for pediatric patients and a one-fourth dose for infants (Cabana et al., 2006). A recent study analyzed a range of brands of probiotics and found that of the 19 brands examined, five did not contain the number of live microorganisms stated on the label (http://www.consumerlab.com/results/probiotics.asp). Because some labels are unreliable, physicians should recommend specific brands known to be of reasonable quality or encourage patients to research brands before purchasing a specific product. Guidance on probiotics can be found at http://www.usprobiotics.org and at the National Center for Complementary and Alternative Medicine's Web site, http:// nccam.nih.gov/heaIth/probiotics/.

Presently, a wide range of dosages for Lactobacillus sp. and other probiotics have been studied in clinical trials and are available, ranging from 100 million to 1.8 trillion CFUs per day, with larger dosages used to reduce the risk of pouchitis relapse. Most studies examined dosages in the range of 1 to 20 billion CFUs per day, although exact dosages for specific indications varied within this range. Generally, higher dosages of probiotics (that is, more than 5 billion CFUs per day in children and more than 10 billion CFUs per day in adults) were associated with a more significant study outcome. The dosages of $S$. boulardii in most studies range between 250 and $500 \mathrm{mg}$ per day (Table 2).

\section{Probiotic products}

Fermented dairy products enriched with probiotic bacteria have developed into one of the most successful 
Table 3. Commercial probiotic products in market (Cutting, 2011; Suvarna and Boby, 2005)*.

\begin{tabular}{|c|c|c|c|}
\hline Product name & Species & Company & Applications \\
\hline Nesvita & $L A B$ & Nestle, India & Gut Probiotic \\
\hline Vizyl & $L A B$ & Unichem, India & Gastrointestinal Health \\
\hline ViBact & $\begin{array}{l}\text { Bacillus mesentricus, Clostridium butyricum, } \\
\text { Streptococcus faecalis, Lactobacillus sporogenes }\end{array}$ & & Lamb Performance \\
\hline Provisacc & & Vetcare India Pvt. Ltd, India & Vaginal Infections, Gastrointestinal health \\
\hline Improval & $\begin{array}{l}\text { Saccharomyces cerevasie, lactobacillus } \\
\text { sporogenes }\end{array}$ & Cadila, India & Vaginal infections \\
\hline Econova & & Glenmark, India & Gastrointestinal health \\
\hline Amul & Lactobacillus acidophilus, & Amul, India & Diabetics \\
\hline Binifit & $\begin{array}{l}\text { Streptococcus faecalis, Clostridium butyricum, } \\
\text { Bacillus mesentricus } L A B\end{array}$ & Ranbaxy, India & Antibiotic associated Diarrhoea (AAD) \\
\hline Actimel $^{\circledR}$ & Lactobacillus casei DN 014001 & Danone, France & Immune booster \\
\hline Yakult $®$ & Lactobacillus casei & Yakult Honsha Co., Ltd, Japan & Gastrointestinal health \\
\hline Proviva & Lactobacillus plantarum & Probi, Lund & Gastrointestinal health \\
\hline Gefilus & Lactobacillus GG & Valio Ltd, Finland & Gastrointestinal health \\
\hline Bifilac & $\begin{array}{l}\text { JPC, Clostridium butyricum, Bacillus mesentricus, } \\
\text { Lactobacillus sporogenes }\end{array}$ & Tablets India Pvt Ltd, India & Irritable bowel syndrome, Diarrhoea. \\
\hline LC1 & Lactobacillus johnsonii & Nestle & Gastrointestinal health \\
\hline Flora Grow & $\begin{array}{l}\text { Bifidobacterium infantis, Bifidobacterium longum, } \\
\text { Bifidobacterium bifidum }\end{array}$ & Arise \& Shine Herbal Products Inc, USA & Gastrointestinal health \\
\hline Biosporin $®$ & $\begin{array}{l}\text { Bacillus subtilis } \\
\text { Bacillus licheniformis }\end{array}$ & $\begin{array}{l}\text { Biofarm, Dniepropetrovsk, Ukraine } \\
\text { Garars, Russia }\end{array}$ & Pyo-speticpost operational complications, bacterial vaginitis, \\
\hline Enterogermina ${ }^{\circledR}$ & Bacillus clausii & Sanofi Winthrop SpA, Milan, Italy & Bacteriotherapy and bacterioprphylaxis of gastrointestinal disorders \\
\hline Biostart & & Microbial Solutions, Johannesburg, South Africa & Aquaculture \\
\hline
\end{tabular}


Table 3. count

\begin{tabular}{|c|c|c|c|}
\hline Lactospore $®$ & $\begin{array}{l}\text { Labeled as Lactobacillus sporogenesbut contains } \\
\text { Bacillus coagulans }\end{array}$ & $\begin{array}{l}\text { Pharmed Medicare, Bangalore, India } \\
\text { http://www.pharmedmedicare.com }\end{array}$ & Gastrointestinal health \\
\hline Florastor $\circledast$ & Saccharomyces boulardii & Biocodex, USA & Gastrointestinal Health \\
\hline LG21 & Streptococcus thermophilus 1131 & Meiji milk products, Tokyo & Gastrointestinal health \\
\hline BioGaiaß & Lactobacillus reuteri SD2112 & BioGaia, North Carolina & Gastrointestinal health \\
\hline Florafit@ & Lactobacillus acidophilus NCFM & Rhodia, Madison & Gastrointestinal health \\
\hline BiopromultiTM & Lactobacillus acidophilus & Akacia Health Care (Pty) Ltd, South Africa & Immune booster \\
\hline Morinaga Bifdus milk & Bifidobacterium longum BB536 & Morinaga Milk Industry Co., Ltd., Japan & Gastrointestinal health \\
\hline PoultryStar@ & $\begin{array}{l}\text { Enterococcus, Pediococcus, Lactobacillus, } \\
\text { Bifidobacterium }\end{array}$ & Biomin, Herzogenburg, Austria & Improved weight gain, decreased mortality, inhibition of enteric pathogens \\
\hline Mitomax® & Pediococcus acidilactici, Saccharomyces boulardii & Imagilin Technology, USA & $\begin{array}{l}\text { Supports digestive system, Reduces stress, Reduces diarrhea, Reduces vomiting, } \\
\text { Relieves constipation, Decreases body odor, Enhances immune response }\end{array}$ \\
\hline
\end{tabular}

*partial list

categories of functional foods. They gave rise to the creation of a completely new category of probiotic products like the daily-dose drinks in small bottles, yoghurt, ice creams, milk based desserts, powdered milk for infants, butter, mayonnaise, cheese, products in the form of capsules or fermented food of vegetable origin. Although there are several dozen products in the market that claim to have probiotic activity representatives of only a handful of species dominate the market or have been used in multiple clinical trials. Some of them are listed in Table 3 . These include strains of $L$. casei, $L$. johnsonii, L. rhamnosus and L. plantarum, which are all of human origin and are known under defined brand names. It has been estimated that there were approximately 70 probiotic-containing products marketed in the world (Shah, 2004), and the list is continuously expanding.

Moreover, probiotic products containing Bacillus species have been in the market for at least 50 years with the Italian product known as Enterogermina ${ }^{\circledR}$ registered in 1958 in Italy as an OTC medicinal supplement (Cutting, 2011). Of the species that have been most extensively examined are B. subtilis, B. clausii, B. cereus, $B$. coagulans and $B$. licheniformis. Spores that are being heat-stable have a number of advantages over other non-spore formers such as Lactobacillus spp., namely, that the product can be stored at room temperature in a desiccated form without any deleterious effect on viability. A second advantage is that the spore is capable of surviving the low $\mathrm{pH}$ of the gastric barrier (Spinosa et al., 2000; Barbosa et al., 2005) which is a limitation for all species of Lactobacillus (Tuohy et al., 2007).

\section{CONCLUSION}

Probiotics are foods that contain live microorganisms.

These microorganisms on metabolite production will give these probiotics their health promoting properties such as boosting immune system, prevent allergies, stop eczema and heal the intestine. Presently the scientific community is at the crossroads, firstly in determining whether probiotics are safe and effective in the treatment of many conditions for which they are already in use. This necessitates addressing basic issues such as dosing, safety and mechanisms of actions of these agents. Other major concern about probiotics is prior use for human consumption alone is insufficient to support clinical studies for registering if this does not match intended use as drug. Finally there exist very few large scale, long term clinical trials conducted on probiotics to support them as "drug". However, available data from medical literature and clinical studies clearly indicate that probiotics have great health potential particularly to overcome threat of use of antibiotic 
over dose and prevalence of antibiotic resistant microorganisms. The future probiotic research should essentially focus and provide more precise information on mechanisms by which probiotics exert their beneficial effects in vivo in various gastrointestinal related diseases and greater acceptance by the medical community.

\section{ACKNOWLEDGEMENT}

We extend our sincere acknowledgement to Prof S Mayo, Research Management Division, Durban University of Technology, South Africa for awarding Post Doctoral fellowship to Dr. K. Suresh Babu Naidu.

\section{REFERENCES}

Adam JK, Bharti O, Naidu KSB (2012). Probiotics: Recent understandings and biomedical applications. Curr trends in Biotechnol.Pharma. 6:1-14.

Barbosa TM, Serra CR, La Ragione RM, Woodward MJ, Henriques, AO (2005). Screening for Bacillus isolates in the broiler gastrointestinal tract. Appl.Environ.Microbiol. 71:968-978.

Bergman AJ, Stevens C, Zhou Y (2006). Pharmacokinetic and pharmacodynamic properties of multiple oral doses of stigliptin, a dipeptidyl peptidase-IV inhibitor: a double blind, randomized, placebo-controlled study in healthy male volunteers. Clin. Ther. 28:55-72.

Boyle RJ, Robins-Browne RM, Tang MLK (2006). Probiotic use in Clinical practice. What are the risks. Am. J. Clin. Nutr. 83:1256-1264.

Cabana MD, Shane AL, Chao C, Hemker MO (2006). Probiotics in primary care pediatrics. Clin. Pediatr. 45:405-410.

Cho I, Blaser MJ (2012). The human microbiome: at the interface of health and disease. Nature.Rev. Gene. 13:260-270

Choi HJ, Ahn JH, Park SH, Do KH, Kim J, Moon Y (2012). Enhanced Wound Healing by Recombinant Escherichia coli Nissle 1917 via Human Epidermal Growth Factor Receptor in Human Intestinal Epithelial Cells: Therapeutic Implication Using Recombinant Probiotics. Infect Immunol. 80:1079-1087

Clarke S, Murphy E, Nilaweera E, Ross P, Shanahan F, O'Toole PW, Cotter PD (2012). The gut microbiota and its relationship to diet and obesity: New insights. Gut Microbes. 3:1-17

Cutting SM (2011). Bacillus probiotics. Food Microbiol. 28:214-220

Dumas ME, Barton RH, Toye A (2006). Metabolic profiling reveals a contribution of gut microbiota to fatty liver phenotype in insulinresistant mice. PNAS. 103:12511-12516.

European Food Safety Authority (2009). Briefing document for Member States and European Commission on the evaluation of Article 13.1 health claims. Parma, Italy, 11 November 2009; EFSA J. 7:1386

Elliott E, Teversham K (2004). An evaluation of nine probiotics available in South Africa, August 2003. South Afr. Med. J. 94:121-124

FAONHO (2006). Probiotic in foods. Health and nutritional properties and guidelines for evaluation. In FAO Food and Nutrition; 2006 pp 85 ISBN 92-5-105513-0. Also available at ftp://ftp.fao.org/docrep/fao/ 009/a0512e/a0512e00.pdf

Food and Drug Administration (2009). Development andapproval process (drugs) [updated 2009 Oct 14; cited 2010 Jun 24]. http://www.fda.gov/Drugs/DevelopmentApprovalProcess/default. htm.

Forssten SD, Sindelar CW, Ouwehand AC (2011). Probiotics from an industrial perspective. Anaerobe.17:410-413.

Gokhale G, Nadkarni A (2007). Probiotic foods market in India soon to be regulated. India Law Journal, 2007, Accessible via http://www.indialawjournal.com/volume3/issue_1/article_by_aditi.html Gupta V, Garg R (2009). Probiotics. Ind J. Med. Microbiol. 27:202-209.

Health Canada. Guidance Document-The Use of Probiotic Microorganisms in Food 2009, Food Directorate, Health Products and
Food Branch, Health Canada, April 2009. Accessible via http://www.hcsc.gc.ca/fn-an/alt_formats/hpfbdgpsa/pdf/legislation/probiotics guidanceorientation_probiotiques-eng.pdf

Kligler B, Hanaway P, Cohrssen A (2007). Probiotics in children. Ped. Clin. N. Am. 54:949-967.

Kligler B, Cohrssen A (2008). Probiotics. Amer fam Phys., 78: 10731078.

Ley RE, Peter J, Turnbaugh, Klein S, Gordon JI (2006). Microbial ecology: Human gut microbes associated with obesity. Nature. 444:1022-1023.

Mattila T, Saarela M (2000). Probiotic functional foods. In: Williams MC, Gibson RG, editors. Functional foods. Washington, DC. Boca Raton: CRC Press LLC. pp. 287-313

Mc Farland LV (2009). Evidence-based review of probiotics for antibiotic-associated diarrhea and Clostridium difficile infections. Anaerobe 15:274-280.

Oliver MM, Reid V (2009). Use of probiotics in Child care. J Ped Health Care. 23:194-197.

Parvez S, Malik A, Kang S Ah, Kim HY (2006). Probiotics and their fermented food products are beneficial for health. J. Appl. Microbiol.100:1171-1185.

Pineiro M, Stanton C (2007). Probiotic bacteria: legislative framework e requirements to evidence basis. J.Nutri. 137:850S-853S.

Quigley EMM (2012). The use of probiotics, prebiotics and synbiotics in the management of irritable bowel syndrome. Eur Gastr.Hepat.Rev. 4:233-236. DOI: 10.1111/j.1574-6968.2012.02593.x

Reid G, Jass J, Sebulsky MT, McCormick JK (2003). Potential use of probiotics in clinical practice. Clin Microbiol Rev. 16: 658-672.

Rivera-Espinoza Y, Gallardo-Navarro Y (2010). Non-dairy probiotic products. Food. Microbiol. 27:1-11.

Saarela M, Mogensen G, Fondén R, Mättö J, Mattila-Sandholm T (2000). Probiotic bacteria: safety, functional and technological properties.J. Biotechnol. 84:197-215

Salminen S, Isolauri E, Salminen E (1996). Clinical uses of probiotics for stabilizing the gut mucosal barrier: successful strains and future challenges. Antonie Van Leeuwenhoek. 70:347-358.

Sanchez B, Ruiz L, Gueimonde M, Madiedo PR, Margolles A (2012). Toward improving technological and functional properties of probiotics in foods, Trends in Food Science \& Technology., doi:10.1016/j.tifs.2012.02.002.

Sanders ME (2009). How do we know when something called "probiotic" is really a probiotic? A guideline for consumers and health care professionals. Functional. Food. Rev. 1:B3-12.

Sharma S, Agarwal N, Verma P (2012). Probiotics: The Emissaries of Health from Microbial World. J. Appl. Pharm. Sci. 2:138-143

Shah NP (2004). Probiotics and prebiotics. Agro-Food. Indust. Hi-tech. 15:13-16.

Shane AL,Cabana MD, Vidry S, Merenstein D,Hummelen R,Ellis CL,Heimbach JT, Hempel S, Lynch SV, Sanders ME, Tancredi DJ (2010). Guide to designing, conducting, publishing and communicating results of clinical studies involving probiotic applications in human participants. Gut Microbes 1:243-253

Spinosa MR, Braccini T, Ricca E, De Felice M, Morelli L, Pozzi G, Oggioni MR (2000). On the fate of ingested Bacillus spores. Res. Microbiol. 151:361-368

Sorokulova I (2008). Preclinical Testing in the Development of Probiotics: A Regulatory Perspective with Bacillus Strains as an Example. Clin. Infec. Dis. 46:92-95

Strober W, Fuss I, Mannon P (2007). The fundamental basis of inflammatory bowel disease. J. Clin. Invest. 17:514-521.

Suvarna VC, Boby VU (2005). Probiotics in human health: a current assessment. Curr. Sci. 88: 1744-1748

Tuohy KM, Pinart-Gilberga M, Jones M, Hoyles L, McCartney AL, Gibson GR (2007). Survivability of a probiotic Lactobacillus casei in the gastrointestinal tract of healthy human volunteers and its impact on the faecal microflora. J.Appl.Microbiol. 102:1026-1032

Wei J, HoukaiLi, Liping Zhao, Jeremy Nicholson K (2008). Drug targeting, Nature Reviews Drug Discovery.7: 123-131. DOl10.1038/nrd2505. 